\title{
SLC Polarized Beam Source Electron Optics Design
}

D. C. Schultz, C. M. Spencer, and A. D. Yeremian

\section{Stanford Linear Accelerator Center, Stanford. CA 94309}

This paper describes the design of the beam-line from the polarized electron gun to the linac injector in the Stanford Linear Collider (SLC). The polarized electron source is a Gats photocathode. requiring $10^{-11}$-Torr-range pressure for adequate quantum efficiency and longevity. The phorocathode is illuminated by 3-nsec-long laser pulses. The quality of the cptics for the $160-\mathrm{k} F$ beam is crucial since electron-simulated gas desorption from beam loss in excess of $0.1 \%$ of the $20-0 \mathrm{C}$ pulses may poison the pho:ocarhode. Our design for the rransport line consists of a differential pumping region isolated by a pair of valves. Focusing is peovided by a pair of Helmholte coils and by several iron-encased solenoidal lenses. Our optics design is based on beam transport simulations using $2 \frac{i}{2}-D$ particleia-ceil codes to model the gur and to solve the fullyrelativistic time-dependent equations of motion in three dimensions fot electrons in the presence of azimuthally symmetric electtomagnetic fields.

The design of the polarized beam source transport system is nearly complete. We are beginning to fabricate two identical systems. One system is to be installed in the \$LC this summer for operation this autumn. A copy is to be installated in a polarized gun test laboratory this summer, in order to test the SLC polarized source prior to operating the source in the SLC, and for future tests of new photocathode guns.

In the present configuration, shown in Figure $\mathrm{L}$, two guns can be mounted on the SLC injector. One gun has a GaAs photocathode suitable for producing a polarized eiectron beam. The other gun, which has a thermionic cathode. has produced the unpolarized bearns used in previous SLC opezations. Both of these guns aim into a " $Y$ ". shaped vatuum chamber jnside a $D C$ bend magnet that can bend the beam from either gun into the SLC injector.

Isolation of the photocathode gun vacuum from the " $Y$ " region is necessary for two reasons: (1) It will be necessary occasionally to remove the photocathode gun from the accelerator and to replace it with a spare. When swapping guns, it is desirable to maintain vacuum in the guns and in the " $\mathrm{Y}$ " chamber. (2) The photocathode demands pressure below $10^{-10}$ torr for adequate quantum efficiency and lifetime. The best pressure attained in the " $\mathrm{Y}$ " chamber is of order $10^{-9}$ torr.

The vacuum system design is described eisewhere in these proceedings.' The goal of photocathode vacuum isolation is met by a pair of all-metal straight-through valve with low magnetic permeability. The valves have $2.9 \mathrm{~cm}$ diameter aperture and are 18-cm long- One valve seals-off the gun. The other valve seals-off the "Y" chamber.

- Work supported by the U.S. Department of Energy under contrace DE-AC03-76SFo0515.
The valves pose a challenge for the optics design because they lengthen the beam transport line and constrict its aperture. A potential source of gas load comes from bean loss. The total charge in the 3-nsec pulse is $2 \mathrm{ODC}$. In order to maintain electron-stimulated gas desorption at an acceptable level. we estimate that beam losses must be less than $0.1 \%$ before the bend. and less than $1 \%$ after the bend.

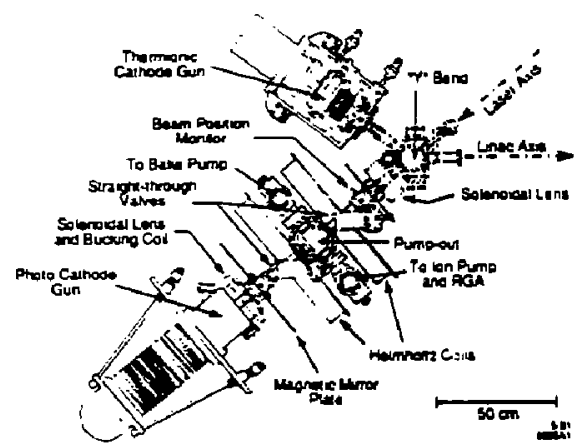

Figure 1: Plan uzew of the $b i C$ gun region. The polarized electron becm emerges from the photocathode gun (at lower (efi), passes through a par of straight-through valves and Heimholtz corls. and is bent through the "Y" chamber into the linac injector. The upper beam-line is the (unpolarized) thermsonse gun.

The opties design is further complicaced by the fact that the photocurrent is not space-charge limited at the bead, tail, and outer radial edges of the beam pulse. This situation arise because the chopped 3-nsec-long laser pulse has finite rise- and fall-times, and because the spatial distribution of the laser spot on the photocathode has edges of diminishing intensity. The temporal distribution used in the simulations is shown in Figure 2.

The basic optics design was calculated using Herrmannsfeldt's electron optics and gun design code to model the gun electrode structure, and the condor electromagnetic simulation code to model the transport line. 5

The magnetic field configuration for the opties design is shown in Figures 3 and 4 , which were calculated by the Poisson computer program. The focusing field necessary to transport the beam efficiently through the pair of low-permeability straight-through valves is provided by a pair of air-core Helmholtz coils. The coils, which are

Presented at the IEEE Particle Accelerator Conference, San Francisco, CA, May 6-9, 1991

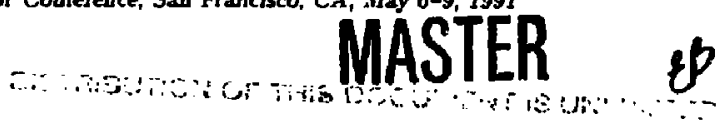




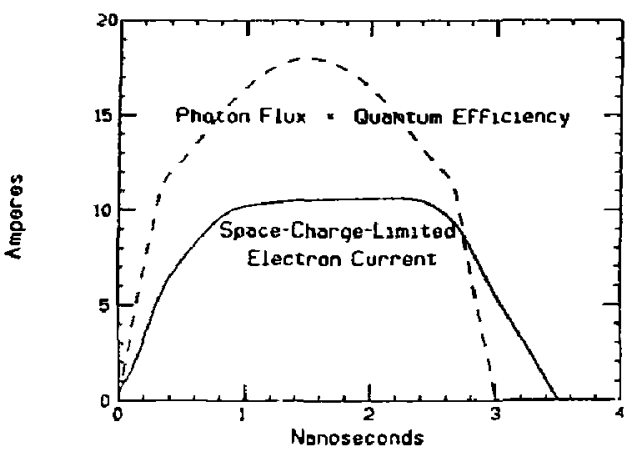

Figure 2: Temporal profile of the laser pulse and the resuling photoemisszon pulse

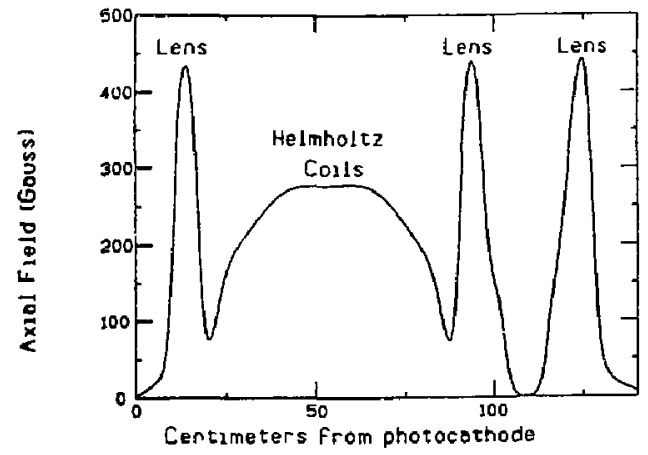

Figure 9: Axial focusing field profile from the photocathade to beyond the "Y" bend chamber, computed by POISSON.

wound from hollow water-cooled conductor, are to be run at half of their 19000-amp-turn peak capability. The coils. which encircle the valves, have $40-\mathrm{cm}$ inner-diameter, 63 $\mathrm{cm}$ outer-diameter, and are separated by $26 \mathrm{~cm}$.

Additional focusing is provided by 2500 -amp-turn iron-encased solenoidal magnetic lenses. Lenses are located $40 \mathrm{~cm}$ on either side of the center of the Helmholtz pair. One of these lenses is mounted on the gun. Another is mounted on the entrance to the "Y" chamber. A third lens is mounted on the exit of the "Y" chamber. The lenses are bakeable to $250^{\circ} \mathrm{C}$.

A 1100-amp-turn bucking coil is wound around the first lens. The coil is made of solid wire, is bakeable to $250^{\circ} \mathrm{C}$, and bas an external cooling water circuit. The purpose of the bucking coil is to zero the DC magnetic fux through the cathode, which is important for producing a low-emittance beam. The normalized beam emittance due to axial field $B_{c}$ through the cathode is $(\mathrm{e} / 2 \mathrm{mc}) R^{2} B_{c}$, where $R$ is the beam radius at the cathode.

The beam envelope, displayed as a superposition of condor's step-by-step snapshots, is displayed in Figure 5.

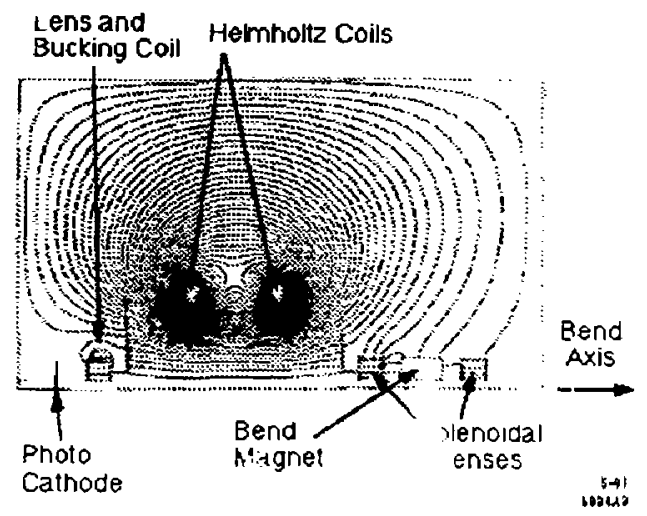

Figure \&: Magnetic flus plof from the procathude to beyond the " $Y$ "bend chamber, compuled d, poIsso.

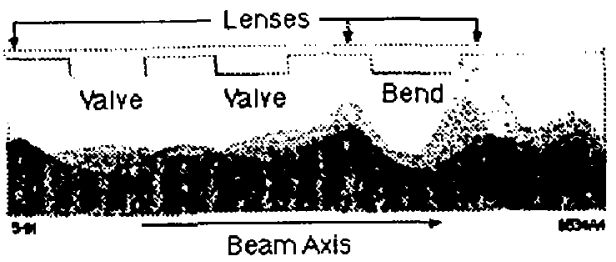

Figure 5: The beam envelope from the photocathode to bryond the bend chamber, computed by condor.

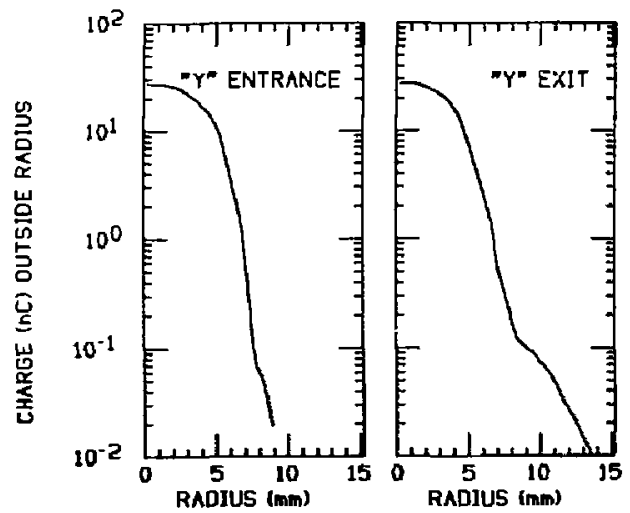

Figure 6: The beam profile before and after the bend. computed by condor. The horizontal axis in both plots extends to $t i$. beam pape wall. The plot indicales that the desired limits on interception (0.02 $\mathrm{nC}$ before the bend and $0.2 \mathrm{nC}$ after the bend) have been met. 
Not alf dots in this figure represent the same amount of charge. A quantiatively precise plot of the bearn profile in the COxDOR simulation is shown in Figure 6 , both before and after the bend.

We are extending our beam dynamics simulation studies through the buncher region of the SLC injector in order to study effect of beam-size and scalloping on capture and bunching, and on depolarization induced by the intense beam's self-fields.

We thank SLAC's Accelerator Theory and Special Projects Department and Mechanical Fabrication Department for technical assistance. In particular, we wish to thank J. E. Clendenin, N. R. Dean, L. A. Klaisner, J. A. Nittall. and B. Woo for assistance.

\section{References}

1 3. E. Clendenin. "The SLC Polarized Election Source" (SLAC-PI-B-5368), presented at the Workshop on Polarized Electron Sources and Electron Spin Polarimeters. Bonn. Federal Republic of Gcrmany. September 6-7. 1990.
2. T. L. Lavine, J. E. Clendenin, E. L. Garwin, E. W: Hoyt, M. W. Hoyt, R. H. Miller, J. A. Nuttall, D. C. Schultz, and D. Wright "SLC Polarized Beam Source Ultra-High Vacuum Design" (SLAC.PUB5454, May 1891), publisbed in these proceedings.

3. The straight-through valves are Vacuum Generators' models CSD-32 being fabricated witlı specjal low magnetic permeability movement mecbanisms.

4. H. B. Herrmannsfeldt, "EGLN-An Electron Optics and Gun Design Program," SLAC Report So. 331.

5. B. Aiminetti ef al. "condor User's Manual," Livermore Computing Systeins Document, Lawrence Livermore National Laboratory, Livermore, California, April, 1988.

6. A. Palevsky and A. T. Drobot, "Application of E-M PIC Codes to Microwave Devices," Proceedings of the Ninth Conf, on Numerical Simulation of Plasmas (Northwestern Iniversity. Evanston, Illinois, June 30-July 2, 1980), Paper PA-2. 